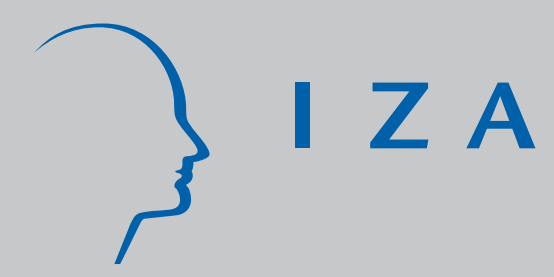

IZA DP No. 3028

Unemployment Duration and Disability: Evidence from Portugal

Dario Sciulli

António Gomes de Menezes

J osé Cabral Vieira

September 2007 


\title{
Unemployment Duration and Disability: Evidence from Portugal
}

\author{
Dario Sciulli \\ University of Pescara and CEEApIA \\ António Gomes de Menezes \\ University of the Azores and CEEApIA \\ José Cabral Vieira \\ University of the Azores, CEEAPIA and IZA
}
Discussion Paper No. 3028
September 2007

\author{
IZA \\ P.O. Box 7240 \\ 53072 Bonn \\ Germany \\ Phone: +49-228-3894-0 \\ Fax: +49-228-3894-180 \\ E-mail: iza@iza.org
}

\begin{abstract}
Any opinions expressed here are those of the author(s) and not those of the institute. Research disseminated by IZA may include views on policy, but the institute itself takes no institutional policy positions.

The Institute for the Study of Labor (IZA) in Bonn is a local and virtual international research center and a place of communication between science, politics and business. IZA is an independent nonprofit company supported by Deutsche Post World Net. The center is associated with the University of Bonn and offers a stimulating research environment through its research networks, research support, and visitors and doctoral programs. IZA engages in (i) original and internationally competitive research in all fields of labor economics, (ii) development of policy concepts, and (iii) dissemination of research results and concepts to the interested public.
\end{abstract}

IZA Discussion Papers often represent preliminary work and are circulated to encourage discussion. Citation of such a paper should account for its provisional character. A revised version may be available directly from the author. 
IZA Discussion Paper No. 3028

September 2007

\section{ABSTRACT \\ Unemployment Duration and Disability: Evidence from Portugal}

In this paper we use Portuguese data on individual (multiple) unemployment spells and apply semi-parametric duration models to investigate the effects of different types of disabilities on (re)employment probabilities. We find that disabled persons with muscular, skeletal, geriatric and sensorial problems experience the longest unemployment spells. Organic (blind, deaf or linguistic) disabilities also significantly reduce the probability of finding a job, while intellectual or psychological disabilities do not. We also find that having previous employment experience and vocational training raise the probability of leaving unemployment into employment. Negative duration dependence and unobserved heterogeneity are also found in the data. Policies that seek to promote job accessibility should take into account the heterogeneous nature of the effects of different disabilities on reemployment.

JEL Classification: J64, I12, C41

Keywords: $\quad$ unemployment duration, disability, hazard models

Corresponding author:

José Cabral Vieira

Department of Economics and Management

University of the Azores

9500 Ponta Delgada

Portugal

E-mail: josevieira@notes.uac.pt 


\section{Introduction}

Many studies in labour economics focus on the situation of disadvantaged groups (for example, low skilled workers, young or older workers, immigrants, females) that are more likely to experiment a mixture of more frequent and longer unemployment spells, lower wages, precarious job conditions, and so on. Disabled persons, however, have only recently started to draw researchers' attention, despite the high likelihood that they are in the weakest position on the labour market out of all disadvantaged groups. ${ }^{1}$ The relative disadvantages of disabled persons are not only dependent on their own characteristics but are also affected by social and work environments and by the lack of services favouring job accessibility. Recently, some authors have gathered evidence on the disadvantaged labour market position of disabled persons. For instance, Kidd, Sloane and Ferko (2000) document that disabled persons experience substantial wage and participation rate differences when compared to non disabled persons. Labour market participation of disabled persons has been one of the most investigated issues regarding disability and labour market outcomes. In fact, Bartel and Taubman (1979), Gannon (2005), among others, showed that having a disability reduces working hours and, more generally, the probability of participating in the labour market. As highlighted by Miranda (2003), the main reason for the higher incidence of labour market non participation among disabled persons is that not only disabled persons experience more difficulties in finding a job according to their abilities but also serious physical barriers continue to exist in the access to buildings and to the public transportation system. However, and as anticipated, in addition to lower labour market participation rates it is quite likely that disabled persons experience longer unemployment spells. In order to shed new light on the relation between disability and unemployment duration, our paper focuses on individual unemployment durations. We propose an analysis that compares the reemployment probabilities of disabled persons and the reemployment probabilities of non disabled persons. We present novel evidence on the effect on the probability of leaving unemployment while distinguishing different types of disabilities. Uncovering the determinants of reemployment probabilities while distinguishing different types of disabilities is of the essence to address policies that aim to answer specific problems deriving from

\footnotetext{
${ }^{1}$ The disadvantaged position of disabled workers may be extended to their respective households. For example, Parodi and Sciulli (2007) argued that, in lack of caring services, the presence of disabled persons needing of care in the household reduces the disposable income of the household, and, concomitantly, increases its poverty risk.
} 
disability and its different forms. In fact, while disabled persons may face common problems regardless of their type of disability, the type of disability itself may affect in a particular way the probability of leaving unemployment into employment. For example, disabled persons with mobility problems will be more likely affected by the presence of (physical) barriers to reach the job place. Disabled persons with organic or intellectual problems, in turn, will most likely experience a lower probability of becoming employed in jobs that require communication with other persons or a specific intellectual ability.

The number of previous contributions studying disability and unemployment duration is rather small and they include Melkersson (1999), Orlando and Patrizio (2006), and Stankunas et al (2006). Melkersson (1999) estimates a duration model with a piece-wise constant hazard with Gamma heterogeneity and competing risks to analyze single unemployment spells for Swedish disabled workers. Melkersson finds that the probability of finding regular employment is smallest for workers with psychological disabilities relative to workers with other disabilities. Orlando and Patrizio (2006) focus on the probability of the disabled worker of being hired through Italian target placement services. Orlando and Patrizio find that employability is positively affected by enrolment spell duration, disabled persons’ personal characteristics, preferences for working hours, enrolment provincial district and the availability of moving into a different working area. In addition, Orlando and Patrizio find that physically disabled persons face a larger probability of being employed when compared to other types of disabilities. Finally, Stankunas et al (2006) document high incidence of depression among the long term unemployed in Lithuania; a problem especially acute for disabled persons since these persons face a relatively high likelihood to find themselves as long term unemployed as a consequence of their relatively low reemployment probabilities.

Our analysis is carried out using monthly data from Portuguese job-centres (Institute of Employment and Vocational Training, IEFP hereafter) that allows us to construct unemployment duration spells and to distinguish non disabled persons from disabled persons characterized by different types of disabilities. In particular, our analysis compares non disabled persons with four arguably homogeneous groups of disabled persons: intellectually or psychologically disabled persons (intellectual problems), blind or linguistic or deaf disabled persons (organic problems), muscularly or skeletally disabled persons (mobility problems), and individuals with other types of disabilities including geriatric, sensorial and aesthetical problems (other problems). Our empirical results are obtained applying semi-parametric hazard models for multiple unemployment spells. To use a hazard function in order to study reemployment probabilities is equivalent to analyse a 
reduced form equation that estimates the determinants of the product of two probabilities, i.e. the probability of receiving a job offer and the probability of accepting it, that constitute the components of the matching process in the labour market (Petrongolo and Pissarides, 2001). Personal, household and job related characteristics are included in our models to control for observable characteristics that may affect reemployment probabilities. It is interesting to note that our semi-parametric approach allows us to control for a plethora of individual, household and job related characteristics. This is of the essence since disabled persons may be more prone than the average person to have, for instance and with no loss of generality, low educational levels or short work histories, perhaps partly as a result of having the disability. By controlling for education and work histories, among many other observable characteristics, we are able to isolate the purged effect of having a specific disability on the probability of finding a job. In addition, our benchmark econometric specification allows for unobservable heterogeneity, in order to avoid estimation bias due to the omission of relevant variables. Finally, we control for business cycle conditions, regional effects and consider labour market tightness variables, namely the monthly levels of the stocks of unemployed and vacancies at the job centre level, to control for matching effects (Petrongolo and Pissarides, 2001).

This paper is organized as follows. Section 2 presents the econometric specification. Section 3 describes the Portuguese institutional background and the data. Section 4 discusses the results. Finally, Section 5 concludes.

\section{Econometric Specification}

The probability of leaving unemployment into employment is estimated applying two semiparametrical hazard models for multiple spells. Our monthly data allow us to analyze individual work histories, including the identification of the origin state, and, in the case of uncensored spells, the transition to the employment state. Therefore, for each individual $i$ it is possible to observe a sequence $t_{i}=\left\{t_{i}^{c}\right\}_{C \in\{1 \ldots C i\}}$ of periods of time (spells) spent in the unemployment state. $t$ indicates the elapsed duration in a particular state and $c$ denotes the $c^{\text {th }}$ spell.

The first model is a piece-wise constant Mixed Proportional Hazard (MPH) model. The MPH model consists in a specification of the Proportional Hazard model that allows for the presence of unobserved heterogeneity across individuals. Lancaster (1990) argues that duration analysis ignoring the presence of unobserved heterogeneity may lead to biased estimates. Lancaster (1979) 
was the first to treat this problem, proposing a Proportional Hazard Model with multiplicative unobserved heterogeneity. We note that unobservable heterogeneity is likely to matter in the problem at hand since differences in tastes, abilities, or other characteristics not reported in the IEFP data most likely condition the probability of leaving unemployment. In addition, the piecewise constant specification allows us to make no assumption about the distribution of unemployment spells. The second model is a Cox Proportional Hazard (PH) model in which unemployment spells pertaining to the same individual are clustered. In fact, since some omitted variables may cause observations within individuals to be correlated over time, the usual standard errors may be incorrect. We tackle this problem using robust standard errors via the Huber-White estimator with additional correction for the effects of clustered data.

The general specification of the hazard rate of the MPH model for the individual $i$ reads:

$$
\lambda_{i}\left(t_{i}^{c} \mid x_{i}, v_{i} ; \beta\right)=\lambda_{0 i}\left(t_{i}^{c}\right) \exp \left(x_{i}^{\prime} \beta\right) v_{i}
$$

$\lambda_{0 i}$ is the baseline hazard and measures the effect of elapsed duration (duration dependence). The baseline hazard is assumed to be piece-wise constant and it consists in a linear function of the elapsed duration with spikes at 6, 12, 24 and 36 months:

$$
\lambda_{0 i}\left(t_{i}^{c}\right)=\exp \left(\begin{array}{l}
a_{1} \ln (t)+a_{2} I(t>6)(\ln (t)-\ln (6))+a_{3} I(t>12)(\ln (t)-\ln (12))+ \\
+a_{4} I(t>24)(\ln (t)-\ln (24))+a_{5} I(t>36)(\ln (t)-\ln (36))
\end{array}\right)
$$

$I$ is an indicator function. This specification allows for non monotone evolutions of the exit rates. $x_{i}$ is a vector of time-invariant individual covariates, which captures personal and job related characteristics, including tightness variables defined at the job centre level. $\beta$ is a vector of unknown parameters to be estimated. $v_{i}$ is a random individual effect which captures the effect of individual heterogeneity. To be more formal, we assume that $v$ is Gamma distributed: ${ }^{2}$

$$
V \mid X \sim \Gamma(1, \theta)
$$

\footnotetext{
${ }^{2}$ Abbring and Van den Berg (2006) show for a large class of hazard models with proportional unobserved heterogeneity that the distribution of heterogeneity among survivors converges, often rapidly, to a gamma distribution.
} 
The unit of time is one month and the covariates are fixed to their values at the beginning of each spell. The individual contribution to the likelihood function of an incomplete (right censored) spell, that is, the probability of surviving in unemployment state until time $t$, can be expressed as follows:

$S\left(t_{i}^{c} \mid W_{i} ; \Omega\right)=\exp \left\{-\Lambda\left(t_{i}^{c} \mid W_{i} ; \Omega\right)\right\}$

where:

$\Lambda=\int_{0}^{t_{j}} \sum_{i} \lambda_{i}\left(s \mid W_{i} ; \Omega\right) \partial s$

is the corresponding integrated hazard function, $W_{i}=\left\{x_{i}, v_{i}\right\}$ is the vector of all observed and unobserved variables and $\Omega$ is the vector of all unknown parameters $(\beta, \theta)$.

The individual contribution to the likelihood function of a completed spell of duration $t_{i}^{c}$ spent in the unemployment state that ends in the employment state is therefore:

$$
f\left(t_{i}^{c} \mid W_{i} ; \Omega\right)=S\left(t_{i}^{c} \mid W_{i} ; \Omega\right) \times \lambda\left(t_{i}^{c} \mid W_{i} ; \Omega\right)
$$

The presence of the unobserved heterogeneity term in (1) implies that we may not condition the individual probabilities on $v_{i}$ since they are unobservable, and we ought to integrate out $v_{i}$ over all its possible values to get the unconditional probabilities. The individual sub-likelihood function related to origin state $j$ and destination state $k$ reads:

$$
L_{i}\left(\Omega \mid t_{i}^{c_{j}}, x_{i}\right)=\int_{-\infty}^{+\infty}\left(\prod_{c=1}^{C_{i}} f\left(t_{i}^{c_{j}} \mid x_{i}, v_{i} ; \Omega\right)^{d^{c_{i}}} \times \prod_{c=1}^{C_{i}} S\left(t_{i}^{c_{j}} \mid x_{i}, v_{i} ; \Omega\right)^{r^{c_{i}}}\right) \times d \Gamma\left(v_{i}\right)
$$

where $c$ indicates the $c^{\text {th }}$ spell in the unemployment state. $d^{c}$ is an indicator variable which equals to one if the individual changed from unemployment state to employment state and zero otherwise, and $r^{c}$ is a dummy variable which equals one if the $c^{\text {th }}$ spell is incomplete and zero otherwise.

The log-likelihood function is obtained by the summation of the sub-log-likelihood function over all $i$ 's: 
$\ln \left(L\left(\Omega \mid t_{i}^{c}, x_{i}\right)\right)=\sum_{c=1}^{C_{i j}} \ln \left(L_{i}\right)$

We now describe our second model. The Cox PH model is a semi-parametric model that makes no assumptions about the form of the baseline hazard and assumes a parametric form for the effect of the predictors on the hazard rate. The general specification of the hazard rate is similar to the MPH specification, except that it does not control for unobserved heterogeneity and the constant term is included in the baseline hazard. Under the Cox PH model the estimated log-likelihood assumes a very similar form than under the MPH model, with the notable aforementioned exception that it does not allow for unobserved heterogeneity. As anticipated, our second model obtains consistent estimates of the standard errors using the Huber-White estimator. The usual standard errors may be incorrect also because of the effects of clustered data. To address this issue, we take advantage of the multiple spell nature of our data and employ the following variance estimator:

$\operatorname{Var}=[I(b)]^{-1} B[I(b)]^{-1}$

where $B$ is a correction factor.

\section{Data and Institutional Background}

Institutional Background

In Portugal, the legal definition of the term "disability” is found in the Framework Law on prevention and rehabilitation of disabled persons (Law 9/89 of 2 May 1989). Under this law, persons who as a result of a congenital or acquired loss of an abnormality of psychological, intellectual, physiological or anatomical structure or function are in a disadvantaged situation with respect to the performance of an activity considered normal taking account their age, gender and the prevailing social and cultural factors, are considered as disabled. The Law 9/89, so-called as the Basic Law of Prevention, Integration and Rehabilitation of the Disabled Persons, foresees that the Portuguese Social Security System must assure the social protection of the disabled persons through 
financial support and diversified modalities of social support that favour their individual autonomy and contribute to their effective integration in the Portuguese society.

In order to increase job finding rates for disabled persons, the New Code of Labour (Law 99/03) specifically stated that "the employer must facilitate the job to the worker with reduced abilities, namely through the adaptation of the tasks and the promotion of adequate vocational training”. The employability of disabled persons was also favoured by the Portuguese Government with the adoption in the year of 2000 of a system of quotas with respect to the presence of disabled persons in the Public Administration. However, the IEFP is responsible for implementing most active employment and vocational training measures promoting, thus, the employability of disabled persons. These measures include: programme of evaluation and occupational orientation of disabled persons, pre-professionalisation of young disabled persons during the last year of their school; readjustment to work after labour accidents or a vocational disease; incentives to the job of disabled persons; support to an independent occupational activity; protected employment; merit prizes for the enterprises that have contributed to the reintegration of disabled persons and, overall, vocational training for disabled persons. ${ }^{3}$ Notwithstanding the aforementioned social concern about disability and labour market outcomes, a rigorous assessment of impact of disability on unemployment duration as pursued here is lacking.

According to the Census 2001 by the Instituto Nacional de Estatística (the National Institute of Statistics; INE) there were about 635.000 disabled persons in Portugal, i.e. $6.1 \%$ of the total Portuguese population. More than 50\% of the disabled persons were older than 55 years old. There are no national statistics about the employment and unemployment rates of disabled persons (Miranda, 2003). However, some studies show that, like in other European countries, it is the case in Portugal that the disabled have a much lower participation rate and a higher unemployment rate than the non disabled. In fact, a study produced by the European Commission (2001), using the European Community Household Panel (ECHP) data for Portugal in 1996, reported a lower participation rate among disabled persons (51.3\%) than non disabled persons (74.4\%), and a higher unemployment rate (6.3\% against 5.3\%). Other national data show that in 1997 22\% of disabled persons were employed (see Miranda, 2003). We also note that data from the last Census available (Census 2001) point to the fact that only $26.2 \%$ of disabled persons were employed. The Census

\footnotetext{
${ }^{3}$ See “Report of Activity 2002”, IEFP.
} 
2001 also highlighted that one of the main difficulties that Portuguese persons with disabilities face is to find a suitable job. In fact, only $25 \%$ of Portuguese disabled persons live from labour incomes.

\section{Data}

The data are drawn from an IEFP dataset that provides information on individuals registered at job centres in Continental Portugal from 1997 to 2002. The IEFP is the agency responsible for running the public employment services, ${ }^{4}$ and it is a division of the Ministry of Labour and Solidarity. The IEFP is also responsible for job broking, vocational guidance, administering employment subsidies, vocational training, and apprenticeship training. The IEFP dataset includes information on job vacancies offered by firms, even if employers are not obliged to notify vacancies to the job centres.

The original IEFP sample has more than 3 millions of observations. To avoid computational problems, we employ in our econometric work a randomized sub-sample equal to $7 \%$ of the original sample. ${ }^{5}$ We focus on unemployment spells starting since June 1998 to avoid missing covariates on training activity. ${ }^{6}$ The IEFP dataset provides daily information about the date of registration at the job centre and the placement date, allowing, thus, the identification of unemployment duration of multiple spells for each individual. The data provide information about personal and job-related characteristics. Spells without the date of placement are considered censored. However, individuals may drop out of the job centres if they fail to present themselves to the job centres' control dates. To avoid the incorrect identification of unemployment duration, we eliminate from our sample spells that terminate in absenteeism or failure to report to the cited control dates. The IEFP data has no full information about the contractual form (permanent or temporary contract) reached after unemployment spells; hence we are unable to carry out a competing risks analysis. ${ }^{7}$

\footnotetext{
4 The IEFP does not have a placement monopoly, since in Portugal both temporary work agency and private employment agencies are allowed.

${ }^{5}$ Descriptive statistics of variables contained in original IEFP dataset and descriptive statistics of randomized sample are available.

${ }^{6}$ We note that individuals registering at the job centres were offered training activities only since June 1998.

${ }^{7}$ IEFP data give information about the contractual form (permanent or temporary contract) only for those individuals who leave unemployment using the job centre services, while this information is not gathered for those individuals who did register at the job centre but found a job by own means.
} 
We analyse individuals aged 16-60 for whom there is information available with respect to all variables controlled for. This selection leaves us two unbalanced panels composed by 92775 observations and 82345 individuals. Given the long unemployment duration that characterizes the Portuguese labour market and the short period analysed here, $88 \%$ of the individuals in our sample experience a single unemployment spell. Censored spells constitute about $69 \%$ of analysed spells.

We consider a set of covariates that controls for observed heterogeneity among individuals. Table 1 reports descriptive statistics, distinguishing by type of disability. Perhaps as expected, disabled persons only represent $0.6 \%$ of our sample. The IEFP data distinguishes ten types of disabilities: intellectual, psychological, blind, deaf, linguistic, muscular, skeletal, aesthetical, sensorial and other types (including geriatric problems). In order to have at our disposal larger subgroups, we cluster the original ten types of disabilities in four arguably homogenous groups, following our reading of the literature. To be more specific, we consider $0.14 \%$ of overall individuals with intellectual or psychological disabilities, $0.18 \%$ with organic (blind, deaf or linguistic) problems, $0.15 \%$ with mobility (muscular or skeletal) problems and, finally, $0.14 \%$ with other forms of disabilities. We control for the following individual and family characteristics: age, introduced in a non-linear way, educational level, marital status and number of dependent persons. The average age of the individuals in our sample is 32.6 years old. $39.5 \%$ of the individuals in our sample are males, $45 \%$ are married, and $61 \%$ do not report any dependent persons. Intermediate educational classes are rather equally observed in the sample and at the extremes of the educational classes we note that while $5.8 \%$ of the individuals have no education at all, $8.7 \%$ of the individuals have 12 or more years of education (including a bachelor degree or a post-graduate degree).

We also control for job characteristics. We consider if the individual is looking for the first job (19.4\% of observations), and, hence, has no previous work experience. We also introduce a set of dummies that captures the motivation underlying the individual's registration at the job centre. In particular, such dummy variables indicate: if the individual was a student at time of registration (6.9\% of observations); if the individual just finished his school career (9.3\% of observations); if the individual has finished a training period with no prior registration at the job centres $(1.8 \%$ of observations); if the individual was fired from his job (18\% of observations); if the individual resigned from his job (12.4\% of observations); and if the individual registered due to the termination of a temporary-contract job: the largest group in our sample, with $36.3 \%$ of observations. Finally, nearly $15 \%$ of observations refer to individuals registered at the job centres for other motivations, i.e. ex housewife or individuals previously working as self-employed (this 
dummy constitutes our base category). We also control for the profession of the individual, distinguishing between managers, specialists, technicians, administrative workers, service workers, agricultural and fishing workers, blue collars, and, finally, individuals without a profession (suggesting no meaningful qualifications). The largest professional group is the blue-collar one, representing $21.5 \%$ of individuals, followed by services (20.5\%) and individuals with no qualifications (20.3\%). Managers and similar professions represent a meagre $1 \%$ of our observations. Two variables are introduced in the regressions to control if individuals received unemployment benefits (30.2\%) or underwent a training experience (47.5\%), following their registration at the job centre.

We include year dummies in the regressions to control for business cycle effects and regional dummies to control, in turn, for local labour markets idiosyncratic effects. In addition, we consider the mean value of the monthly wage distribution at the job-centre level to control for demand side effects. Finally, we consider monthly labour market tightness variables at the job centre level, namely stock values of unemployment $(U)$ and vacancies $(V)$ to capture potential congestion or agglomeration effects in the matching process. ${ }^{8}$ To construct the stock values of unemployment and vacancies we use information from the IEFP dataset dating back to January 1997 to accumulate flow values in order to construct stocks for the period under analysis, which is from June 1998 onwards. The average value of the usual labour market tightness indicator $(V / U)$ is about 0.015 .

When we compare descriptive statistics between disabled and non disabled persons we find that disabled persons are more likely to be males, single, without dependent persons, and with no formal education. Moreover, disabled persons are also more likely to be looking for their first job and involved in vocational training programmes.

\section{Results}

Figure 1 and Table 2 report preliminary evidence on the differences in the probability of leaving unemployment by disability type. Hazard rates estimated using the Kaplan-Meier method are systematically larger for non disabled persons than for disabled persons, with the notable exception for persons with an intellectual or psychological disability, who present a higher and

\footnotetext{
${ }^{8}$ Using stock values of unemployment and vacancies is equivalent to apply a random matching approach to estimate the matching function (Petrongolo 2001).
} 
increasing hazard rate for unemployment durations longer than forty months. Hazard rates related to other disabilities show a substantially negative trend, even if the decreasing rate is stronger in the first months of the unemployment period, just to tamper off after 18-20 months of unemployment duration. Further evidence on the differences in the hazard rates across different types of disabilities are obtained through a log-rank test that rejects the null hypothesis of equality of survival functions (chi2 statistic is equal to 46.53). Table 3 reports mean unemployment durations by disability types. Inspection of Table 3 shows that persons with disabilities experience longer unemployment durations than persons with no disabilities (23.46 months). Quite interestingly, the differences in unemployment durations between a given disability type and no disability are all statistically significant with the exception of an intellectual or psychological disability. Disabled persons with an intellectual or psychological disability experience a longer average unemployment duration (24.71 months) than non disabled persons. However, this difference is not statistically significant, as mentioned above. On the contrary, unemployment duration is significantly higher for other types of disabilities. To be more specific, we found that persons with an organic disability experience higher unemployment durations (25.72 months on average) with the largest average unemployment duration being found for disabled persons with a geriatric or an aesthetical or a sensorial disability (28.31 months). Disabled persons with muscular or skeletal disabilities undergo quite long unemployment spells (27.77 months on average), indicating that mobility impediments may be relevant to explain reemployment probabilities. Finally, we underline that hazard functions show a monotone and decreasing shape, indicating the existence of negative duration dependence, i.e. reemployment probabilities decrease as unemployment duration increases (see Table 4 for the piece-wise constant MPH model and Figure 2 for Cox PH model). This finding may be explained in terms of ranking ${ }^{9}$ or loss of skills during unemployment.

The estimation results obtained applying the semi-parametric hazard models confirm the preliminary evidence aforementioned (Table 4). In fact, we find significant differences in the probability of leaving unemployment among disabled and non disabled persons and negative duration dependence.

Quite interestingly, and rather reassuringly, whenever statistically significant the estimated hazard ratios of our covariates show the same sign both in the piece-wise MPH model and in the

\footnotetext{
${ }^{9}$ Blanchard and Diamond (1994) show that if firms rank unemployed workers and hire those with the shortest spells of unemployment, then the exit rate from unemployment is a decreasing function of duration.
} 
Cox PH model, even if some differences do exist in terms of their magnitudes. Differences in reemployment probabilities with respect to disability types are identified using specific dummies, in which the basecategory is the non disabled state. Both models show that disabled persons with organic, muscular/skeletal (namely mobility) or other (geriatric, sensorial or aesthetical) problems have lower reemployment probabilities than non disabled persons. To be more specific, the reemployment probability for persons with an organic disability is about $1 / 3$ smaller than for non disabled persons. Disabled persons with a muscular/skeletal disability or some other disability face a reemployment probability $40 \%$ smaller than non disabled persons, according to the piece-wise constant model estimates. The Cox PH model, in turn, suggests even more striking differences: reemployment probabilities are about 52\%-56\% smaller for persons with a muscular/skeletal disability or some other disability type when compared to non disabled persons. Finally, our estimates indicate that having an intellectual or psychological disability does not significantly affect the probability of finding a job. Therefore, and taken at face value, these results support the existence of strong and negative effects associated to mobility problems (for example having a muscular or skeletal disability or being blind) and may justify the importance of promoting measures that favour the mobility of disabled persons and job accessibility, in order to increase their reemployment probabilities.

We now turn to a discussion on the effects of personal, household and job related characteristics on the probability of finding job. We find that the probability of finding a job is positively affected by age, albeit at a decreasing rate. Being married and having one or two dependents increase the probability of finding a job. According to the piece-wise constant model estimates, being a male decreases the probability of leaving unemployment by $2.6 \%$. However, the Cox model estimates do not confirm this finding. Quite interestingly, we find that having some educational level reduces the reemployment probability by $15 \%-20 \%$. This result may be explained by the fact that lowly educated individuals are over represented at job centres, implying that vacancies registered by firms at job centres are more likely to present low skill requirements. An additional explanation may owe to lower reservation wages for individuals with no or low schooling levels and, concomitantly, higher job acceptance rates. With respect to registration motives, we note that workers who are looking for their first job display significantly lower hazard ratios. In this sense, having a work history has a significantly positive effect on reemployment probabilities. Individuals who registered at the job centre after a dismissal, a resignation, or after the end of a temporary job are, thus, more likely find a new job after a given unemployment period than 
individuals with no prior work history. We note that the reemployment probability of individuals with previous temporary work experiences is $45 \%$ higher and $110 \%$ higher, according to the MPH model and to the Cox model, respectively, when compared to the base category. Better qualified individuals, i.e. managers, specialists and technicians, are more likely to spend more time unemployed. On the contrary, blue-collar workers face higher hazard rates. By the same token, agricultural and fishing workers also face quite high hazard rates. These findings also suggest that vacancies registered at the job centres most likely present low skill requirements.

According to the Cox PH model estimates, individuals receiving unemployment benefits show an unexpected higher probability of leaving unemployment. However, the piece-wise constant model does not confirm this result. Both models confirm that receiving vocational training during the unemployment spell increases the probability of finding a job, with point estimates of $9 \%$ and $13.5 \%$, depending on the model considered. With respect to regional effects, we note that individuals living in the region "North" face a lower probability of leaving unemployment, while individuals living in the regions "Centro”, “Alentejo” and "Algarve” are more likely to leave unemployment everything else the same. Labour market tightness variables show the expected signs, with the probability of leaving unemployment decreasing with the stock of unemployed (congestion problems), and increasing with the stock of vacancies available. Finally, and according to the MPH model estimates, we find a statistically significant presence of unobserved heterogeneity. This latter result is indicative of the relevance of controlling for unobservable terms in order to avoid estimation biases.

\section{Conclusions}

This paper investigates the effects of having a disability on individual reemployment probabilities and contributes, thus, to the sparse empirical literature on disability and labour market outcomes. Using Portuguese data, we estimate two semi-parametric duration models to multiple unemployment spells and find evidence that disabled persons experience longer unemployment spells. Quite interestingly, we find that different types of disabilities affect the probability of leaving unemployment in different ways. Taking the non disabled persons as our base category, we note that both a piece-wise constant MPH model and a Cox PH model indicate that having an organic disability, i.e. being blind or deaf or having linguistic problems, reduces reemployment probabilities by about one third. According to our MPH specification, having muscular or skeletal or other types 
of disabilities, i.e. geriatric, sensorial and aesthetical disabilities, decrease the probability of leaving unemployment by 40\%. In turn, our Cox $\mathrm{PH}$ model indicates that having the latter muscular or skeletal or other types of disabilities reduces reemployment probabilities by more than $50 \%$. However, and on the contrary, having an intellectual or psychological disability does not significantly decrease the probability of finding a job. These results suggest that individuals with mobility impediments (having a muscular or skeletal disability or being blind) are more likely to undergo long unemployment spells. Therefore, our results support the importance of promoting mobility for the disabled and, concomitantly, job accessibility, in order to increase reemployment probabilities for disabled persons. With respect to individual characteristics we note that having previous job experiences and undergoing vocational training both increase reemployment probabilities. Negative duration dependence, with the notable exception of the group of persons with an intellectual disability, and significant unobserved heterogeneity are also found in the data.

\section{References}

Abbring, J.H. and G.J. van den Berg (2006) “The Unobserved Heterogeneity Distribution in Duration Analysis”, Tinburgen Institute Discussion Paper, n. 2006-059/3.

Bartel, A. and P. Taubman (1979) "Health and Labour Market Success: The Role of Various Diseases”, The Review of Economics and Statistics, vol. 59 (1), pp. 1-8.

Blanchard, O.J. and P. Diamond (1994) "Ranking, Unemployment Duration and Wages”, Review of Economic Studies, n. 61, pp. 417-434.

Cleves, M.A., W.W. Gould and R.G. Gutierrez (2004) “An Introduction to Survival Analysis Using STATA”, Revised Edition, STATA Press.

European Commission (2001) The Employment Situation of Persons with Disabilities in the European Union, http://ec.europa.eu/employment_social/publications/2001/cev501003_en.pdf.

Gannon, B. (2005) “A Dynamic Analysis of Disability and Labour Force Participation in Ireland 1995-2000”, Health Economics, vol. 14, n.9, pp.

Heckman, J.J. and B. Singer (1984) "A Method for Minimizing the Impact of Distributional Assumptions in Econometric Models for Duration Data”, Econometrica, vol. 58, pp. 1411-1441; IEFP (2002) Report of Activity 2002.

Instituto Nacional de Estatística (2001), Census 2001. 
Kidd, M., P. Sloane and I. Ferko (2000) "Disability and the Labour Market: An Analysis of British Males”, Journal of Health Economics, vol. 19, pp. 961-981.

Kiefer, N.M. (1988) “Economic Duration Data and Hazard Functions”, Journal of Economic Literature, vol. XXVI (June), pp. 646-679.

Lancaster, T. (1979) "Econometric Methods for the Duration of Unemployment" Econometrica, July, n. 47(4), pp. 965-979.

Lancaster, T. (1990) “The Econometric Analysis of Transition Data”, Cambridge University Press.

Melkersson, M. (1999) "Unemployment Duration and Heterogeneous Search Behaviour among Swedish Disabled Workers”, Working Papers Series 1999:5, IFAU-Institute for Labor Market Policy Evaluation.

Miranda, H. (2003) "Disability Management in the Netherlands", Peer Review Programme of the European Employment Strategy, Den Haag, The Netherlands 24-25 ${ }^{\text {th }}$ November 2003, http://pdf.mutual-learning-employment.net/.

Orlando N. and M. Patrizio (2006) “Il Collocamento Mirato dei Disabili: L’Applicazione della Legge 68/1999 nella Provincia Autonoma di Bolzano”, in Aspetti Socio-Economici della Disabilità: Atti del Convegno, Pescara Marzo 2006 (Eds. G. Parodi), Aracne, Roma.

Parodi, G. and D. Sciulli (2007) "Disability in Italian Households: Income, Poverty and Labour Market Participation”, Applied Economics, forthcoming.

Petrongolo B. (2001) "Reemployment Probabilities and Returns to Matching”, Journal of Labor Economics, n.19, issue 3, pp. 716-741.

Petrongolo, B. and C.A. Pissarides (2001) "Looking into the Black Box: A Survey of the Matching Function”, Journal of Economic Literature, n. 39 (June), pp.390-431.

Stankunas M., R. Kalediene, S. Starkuviene and V. Kapustinskiene (2006) "Duration of Unemployment and Depression: A Cross-Sectional Survey in Lithuania“, BMC Public Health, n. 6, pp. 174-183.

van den Berg, G.J. (2001) “Duration Models: Specification, Identification, and Multiple Durations”, In Handbook of Econometrics, Volume V, Ed. J.J. Heckman and E. Leamer. Amsterdam: North Holland. 
Table 1. Descriptive Statistics

\begin{tabular}{|c|c|c|c|c|c|c|c|c|c|c|c|c|c|}
\hline \multirow{3}{*}{ Variables } & & \multirow{2}{*}{\multicolumn{2}{|c|}{ All }} & \multirow{2}{*}{\multicolumn{2}{|c|}{ No Disabled }} & \multicolumn{8}{|c|}{ Disabled } \\
\hline & & & & & & \multicolumn{2}{|c|}{ Intellectual } & \multicolumn{2}{|c|}{ Organic } & \multicolumn{2}{|c|}{ Muscolar/Skeletal } & \multicolumn{2}{|c|}{ Other } \\
\hline & & Mean & S.d. & Mean & S.d. & Mean & S.d. & Mean & S.d. & Mean & S.d. & Mean & S.d. \\
\hline$\overline{\text { Age }}$ & Age of individual & 32,633 & 11,761 & 32,639 & 11,768 & 25,885 & 7,998 & 32,398 & 10,568 & 33,718 & 11,077 & 34,090 & 10,370 \\
\hline Male & Male individual & 0,395 & 0,489 & 0,394 & 0,489 & 0,592 & 0,493 & 0,542 & 0,500 & 0,648 & 0,479 & 0,694 & 0,463 \\
\hline Married & Married individual & 0,450 & 0,498 & 0,452 & 0,498 & 0,092 & 0,291 & 0,301 & 0,460 & 0,324 & 0,470 & 0,284 & 0,452 \\
\hline No Dependent & No dependent people & 0,609 & 0,488 & 0,608 & 0,488 & 0,915 & 0,279 & 0,687 & 0,465 & 0,704 & 0,458 & 0,664 & 0,474 \\
\hline One Dependent & One dependent people & 0,193 & 0,395 & 0,193 & 0,395 & 0,046 & 0,211 & 0,169 & 0,376 & 0,141 & 0,349 & 0,187 & 0,391 \\
\hline Two Dependent & Two dependent people & 0,137 & 0,344 & 0,138 & 0,344 & 0,031 & 0,173 & 0,108 & 0,312 & 0,085 & 0,279 & 0,090 & 0,287 \\
\hline No Education & No education & 0,058 & 0,233 & 0,058 & 0,234 & 0,038 & 0,193 & 0,018 & 0,134 & 0,035 & 0,185 & 0,015 & 0,122 \\
\hline Education4 & 4 years of education & 0,231 & 0,421 & 0,230 & 0,421 & 0,408 & 0,493 & 0,211 & 0,409 & 0,204 & 0,405 & 0,328 & 0,471 \\
\hline Education6 & 6 years of education & 0,217 & 0,412 & 0,216 & 0,412 & 0,231 & 0,423 & 0,265 & 0,443 & 0,282 & 0,451 & 0,254 & 0,437 \\
\hline Education6 & 9 years of education & 0,192 & 0,394 & 0,192 & 0,394 & 0,200 & 0,402 & 0,211 & 0,409 & 0,176 & 0,382 & 0,194 & 0,397 \\
\hline Education11_12 & 11 or 12 years of education & 0,216 & 0,411 & 0,216 & 0,412 & 0,023 & 0,151 & 0,187 & 0,391 & 0,225 & 0,419 & 0,164 & 0,372 \\
\hline Education_over12 & over 12 years of education & 0,087 & 0,282 & 0,087 & 0,282 & 0,100 & 0,301 & 0,108 & 0,312 & 0,077 & 0,268 & 0,045 & 0,208 \\
\hline No Disability & No disability & 0,994 & 0,078 & - & - & - & - & - & - & - & - & - & - \\
\hline Intellectual & Intellectaul or psychological problems & 0,001 & 0,037 & - & - & - & - & - & - & - & - & - & - \\
\hline Organic & Blind, deaf or linguistic problems & 0,002 & 0,042 & - & - & - & - & - & - & - & - & - & - \\
\hline Other & Geriatric, sensorial or aesthetical problems & 0,001 & 0,038 & - & - & - & - & - & - & - & - & - & - \\
\hline First job & Looking for first job & 0,194 & 0,395 & 0,193 & 0,395 & 0,546 & 0,500 & 0,355 & 0,480 & 0,296 & 0,458 & 0,172 & 0,378 \\
\hline Student & & 0,069 & 0,253 & 0,069 & 0,253 & 0,077 & 0,268 & 0,084 & 0,279 & 0,099 & 0,299 & 0,045 & 0,208 \\
\hline Ex-Student & & 0,093 & 0,291 & 0,093 & 0,291 & 0,131 & 0,338 & 0,133 & 0,340 & 0,092 & 0,289 & 0,015 & 0,122 \\
\hline End of Training Period & & 0,018 & 0,133 & 0,018 & 0,131 & 0,208 & 0,407 & 0,048 & 0,215 & 0,056 & 0,231 & 0,067 & 0,251 \\
\hline Fired & Motivation to the registration & 0,180 & 0,384 & 0,180 & 0,384 & 0,085 & 0,279 & 0,163 & 0,370 & 0,162 & 0,370 & 0,164 & 0,372 \\
\hline Resignation & & 0,124 & 0,330 & 0,125 & 0,330 & 0,038 & 0,193 & 0,120 & 0,327 & 0,085 & 0,279 & 0,119 & 0,325 \\
\hline End of Temporary Job & & 0,363 & 0,481 & 0,364 & 0,481 & 0,138 & 0,347 & 0,241 & 0,429 & 0,113 & 0,317 & 0,254 & 0,437 \\
\hline Other motivation & & 0,153 & 0,360 & 0,152 & 0,359 & 0,323 & 0,469 & 0,211 & 0,409 & 0,394 & 0,490 & 0,336 & 0,474 \\
\hline Managers and Direction & & 0,010 & 0,100 & 0,010 & 0,101 & 0,000 & 0,000 & 0,006 & 0,078 & 0,000 & 0,000 & 0,000 & 0,000 \\
\hline Specialist and Teachers & & 0,077 & 0,267 & 0,077 & 0,267 & 0,000 & 0,000 & 0,030 & 0,171 & 0,056 & 0,231 & 0,015 & 0,122 \\
\hline Technicians & & 0,075 & 0,263 & 0,075 & 0,263 & 0,008 & 0,088 & 0,120 & 0,327 & 0,099 & 0,299 & 0,082 & 0,276 \\
\hline White Collars & & 0,170 & 0,376 & 0,170 & 0,376 & 0,115 & 0,321 & 0,211 & 0,409 & 0,415 & 0,495 & 0,172 & 0,378 \\
\hline Services & $\mathrm{P}$ & 0,205 & 0,404 & 0,205 & 0,404 & 0,108 & 0,311 & 0,133 & 0,340 & 0,063 & 0,245 & 0,134 & 0,342 \\
\hline Agricultural and Fishing & & 0,044 & 0,206 & 0,044 & 0,206 & 0,131 & 0,338 & 0,024 & 0,154 & 0,021 & 0,144 & 0,037 & 0,190 \\
\hline Blue Collars & & 0,215 & 0,411 & 0,216 & 0,411 & 0,123 & 0,330 & 0,199 & 0,400 & 0,141 & 0,349 & 0,179 & 0,385 \\
\hline No Qualified & & 0,203 & 0,402 & 0,202 & 0,402 & 0,515 & 0,502 & 0,277 & 0,449 & 0,204 & 0,405 & 0,381 & 0,487 \\
\hline Wage & Wage offered & 40,955 & 90,857 & 40,943 & 90,975 & 41,101 & 42,173 & 38,916 & 50,917 & 48,785 & 106,739 & 43,791 & 59,643 \\
\hline Norte & & 0,346 & 0,476 & 0,346 & 0,476 & 0,223 & 0,418 & 0,337 & 0,474 & 0,317 & 0,467 & 0,321 & 0,469 \\
\hline Centro & & 0,162 & 0,368 & 0,162 & 0,368 & 0,269 & 0,445 & 0,199 & 0,400 & 0,218 & 0,415 & 0,127 & 0,334 \\
\hline Lisboa & Region of residence & 0,362 & 0,480 & 0,361 & 0,480 & 0,385 & 0,488 & 0,386 & 0,488 & 0,380 & 0,487 & 0,448 & 0,499 \\
\hline Alentejo & & 0,076 & 0,265 & 0,076 & 0,266 & 0,077 & 0,268 & 0,042 & 0,202 & 0,021 & 0,144 & 0,045 & 0,208 \\
\hline Algarve & & 0,054 & 0,226 & 0,054 & 0,226 & 0,046 & 0,211 & 0,036 & 0,187 & 0,063 & 0,245 & 0,060 & 0,238 \\
\hline Y98 & & 0,151 & 0,358 & 0,151 & 0,358 & 0,100 & 0,301 & 0,139 & 0,347 & 0,113 & 0,317 & 0,194 & 0,397 \\
\hline Y99 & & 0,227 & 0,419 & 0,227 & 0,419 & 0,323 & 0,469 & 0,247 & 0,433 & 0,268 & 0,444 & 0,201 & 0,403 \\
\hline Y00 & Year dummies & 0,206 & 0,404 & 0,206 & 0,404 & 0,192 & 0,396 & 0,175 & 0,381 & 0,254 & 0,437 & 0,187 & 0,391 \\
\hline Y01 & & 0,199 & 0,399 & 0,199 & 0,399 & 0,169 & 0,376 & 0,205 & 0,405 & 0,183 & 0,388 & 0,209 & 0,408 \\
\hline Y02 & & 0,218 & 0,413 & 0,218 & 0,413 & 0,215 & 0,413 & 0,235 & 0,425 & 0,183 & 0,388 & 0,209 & 0,408 \\
\hline lnstock_u & Log of stock of unemployment & 8,931 & 0,780 & 8,931 & 0,780 & 8,936 & 0,759 & 8,902 & 0,784 & 8,997 & 0,701 & 8,881 & 0,792 \\
\hline lnstock_v & Log of stock of vacancies & 4,615 & 0,739 & 4,614 & 0,739 & 4,781 & 0,737 & 4,666 & 0,766 & 4,786 & 0,682 & 4,700 & 0,683 \\
\hline
\end{tabular}

Source: Own elaboration based on IEFP data. 
Table 2. Survival Function by Type of Disability

\begin{tabular}{c|ccccc}
\hline \multirow{2}{*}{ Duration } & Non disabled & \multicolumn{4}{|c}{ Disabled } \\
\cline { 2 - 6 } & & Intellectual & Organic & Muscolar/Skeletal & Other \\
\hline 1 & 0.9482 & 0.9100 & 0.9662 & 0.9756 & 0.9821 \\
5 & 0.8363 & 0.8032 & 0.8539 & 0.9095 & 0.9104 \\
10 & 0.7717 & 0.7727 & 0.8151 & 0.8841 & 0.8802 \\
15 & 0.7211 & 0.7284 & 0.7984 & 0.8655 & 0.8802 \\
20 & 0.6847 & 0.7165 & 0.7984 & 0.8655 & 0.8696 \\
25 & 0.6568 & 0.7043 & 0.7794 & 0.8655 & 0.8572 \\
30 & 0.6302 & 0.6553 & 0.7794 & 0.8544 & 0.8572 \\
35 & 0.6094 & 0.6393 & 0.7455 & 0.8406 & 0.8276 \\
40 & 0.5878 & 0.6393 & 0.7455 & 0.8219 & 0.7908 \\
45 & 0.5688 & 0.6393 & 0.7455 & 0.7963 & 0.7908 \\
50 & 0.5515 & 0.4947 & 0.7179 & 0.7963 & 0.7908 \\
55 & 0.5293 & 0.2968 & 0.7179 & 0.7963 & 0.7908 \\
\hline
\end{tabular}

Source: Own elaboration based on IEFP data.

Table 3. Mean Unemployment Duration

\begin{tabular}{lcccl}
\hline & Mean & S.d. & t-statistic & \\
\hline No disability & 23.46 & 17.42 & & \\
\hline Intellectual & 24.71 & 17.49 & -0.819 & \\
Organic & 25.72 & 18.06 & -1.652 & $*$ \\
Muscolar/Skeletal & 27.77 & 16.29 & -2.947 & $* * *$ \\
Other & 28.31 & 17.34 & -3.22 & $* * *$ \\
\hline
\end{tabular}

Source: Own elaboration based on IEFP data. 
Table 4. Estimation Results

\begin{tabular}{|c|c|c|c|c|c|c|}
\hline \multirow[b]{2}{*}{ Variables } & \multicolumn{3}{|c|}{ Piece-Wise MPH model } & \multicolumn{3}{|c|}{ Cox PH model } \\
\hline & Hazard ratio & s.e. & & Hazard ratio & r.s.e. & \\
\hline Age & 1.022 & 0.005 & $* * *$ & 1.026 & 0.005 & $* * *$ \\
\hline Age square & 1.000 & 0.000 & $* * *$ & 0.999 & 0.000 & $* * *$ \\
\hline Male & 0.974 & 0.014 & * & 1.017 & 0.017 & \\
\hline Married & 1.031 & 0.017 & $*$ & 1.110 & 0.022 & $* * *$ \\
\hline One Dependent & 1.070 & 0.020 & $* * *$ & 1.073 & 0.024 & $* * *$ \\
\hline Two Dependent & 1.049 & 0.023 & ** & 1.039 & 0.028 & \\
\hline Three Dependent & 0.981 & 0.030 & & 0.845 & 0.032 & $* * *$ \\
\hline Education4 & 0.784 & 0.029 & $* * *$ & 0.747 & 0.034 & $* * *$ \\
\hline Education6 & 0.800 & 0.029 & $* * *$ & 0.752 & 0.033 & $* * *$ \\
\hline Education6 & 0.800 & 0.029 & $* * *$ & 0.760 & 0.034 & $* * *$ \\
\hline Education11_12 & 0.791 & 0.028 & $* * *$ & 0.757 & 0.032 & $* * *$ \\
\hline Education_over12 & 0.841 & 0.030 & $* * *$ & 0.795 & 0.035 & $* * *$ \\
\hline First job & 0.922 & 0.039 & $*$ & 0.847 & 0.039 & $* * *$ \\
\hline Student & 1.143 & 0.053 & $* * *$ & 1.203 & 0.061 & $* * *$ \\
\hline Ex-Student & 1.037 & 0.046 & & 1.228 & 0.060 & $* * *$ \\
\hline End of Training & 0.963 & 0.053 & & 1.177 & 0.072 & $* * *$ \\
\hline Fired & 1.239 & 0.031 & $* * *$ & 1.675 & 0.049 & $* * *$ \\
\hline Resignation & 1.055 & 0.030 & $*$ & 1.245 & 0.041 & $* * *$ \\
\hline End of Temporary Job & 1.441 & 0.032 & $* * *$ & 2.100 & 0.056 & $* * *$ \\
\hline Managers and Direction & 0.781 & 0.056 & $* * *$ & 0.769 & 0.060 & $* * *$ \\
\hline Specialist and Teachers & 0.855 & 0.030 & $* * *$ & 0.828 & 0.034 & $* * *$ \\
\hline Technicians & 0.933 & 0.028 & $* *$ & 0.918 & 0.031 & $* *$ \\
\hline White Collars & 0.998 & 0.023 & & 0.987 & 0.026 & \\
\hline Services & 0.972 & 0.020 & & 0.949 & 0.024 & $* *$ \\
\hline Agricultural and Fishing & 2.051 & 0.064 & $* * *$ & 2.496 & 0.104 & $* * *$ \\
\hline Blue Collars & 1.026 & 0.021 & & 1.117 & 0.027 & $* * *$ \\
\hline Benefit & 1.066 & 0.045 & & 1.242 & 0.066 & $* * *$ \\
\hline Training & 1.135 & 0.015 & $* * *$ & 1.087 & 0.017 & $* * *$ \\
\hline Wage & 1.000 & 0.000 & & 1.000 & 0.000 & \\
\hline Norte & 0.874 & 0.014 & $* * *$ & 0.824 & 0.016 & $* * *$ \\
\hline Centro & 0.972 & 0.019 & & 1.062 & 0.023 & $* * *$ \\
\hline Alentejo & 1.179 & 0.037 & $* * *$ & 1.058 & 0.043 & \\
\hline Algarve & 1.090 & 0.029 & $* * *$ & 1.425 & 0.047 & $* * *$ \\
\hline Y99 & 1.283 & 0.026 & $* * *$ & 1.240 & 0.030 & $* * *$ \\
\hline Y 00 & 1.011 & 0.026 & & 1.433 & 0.042 & $* * *$ \\
\hline Y 01 & 0.695 & 0.020 & $* * *$ & 1.641 & 0.059 & $* * *$ \\
\hline Y02 & 0.256 & 0.008 & $* * *$ & 1.693 & 0.070 & $* * *$ \\
\hline lnstock_u & 0.823 & 0.011 & $* * *$ & 0.825 & 0.013 & $* * *$ \\
\hline lnstock_v & 1.149 & 0.014 & $* * *$ & 1.114 & 0.016 & $* * *$ \\
\hline Intellectual & 1.149 & 0.194 & & 0.995 & 0.227 & \\
\hline Organic & 0.655 & 0.120 & $* *$ & 0.669 & 0.136 & $* *$ \\
\hline Muscolar/Skeletal & 0.600 & 0.138 & $* *$ & 0.481 & 0.132 & $* * *$ \\
\hline Other & 0.599 & 0.141 & $* *$ & 0.444 & 0.128 & $* * *$ \\
\hline t06 & 201.150 & 5.139 & $* * *$ & & & \\
\hline t712 & 48.374 & 1.349 & $* * *$ & & & \\
\hline $\mathrm{t} 1324$ & 15.858 & 0.449 & $* * *$ & & & \\
\hline $\mathrm{t} 2536$ & 4.411 & 0.146 & $* * *$ & & & \\
\hline Theta & 0.094 & 0.008 & $* * *$ & & & \\
\hline Log-likelihood & -5 & 87.4 & & -30 & 05.8 & \\
\hline Observations & & & & & & \\
\hline Individuals & & & & & & \\
\hline LR chi2 & 52 & 3.43 & & & .31 & \\
\hline
\end{tabular}

Source: our elaboration on IEFP data 
Figure 1. Hazard Rates by Types of Disability

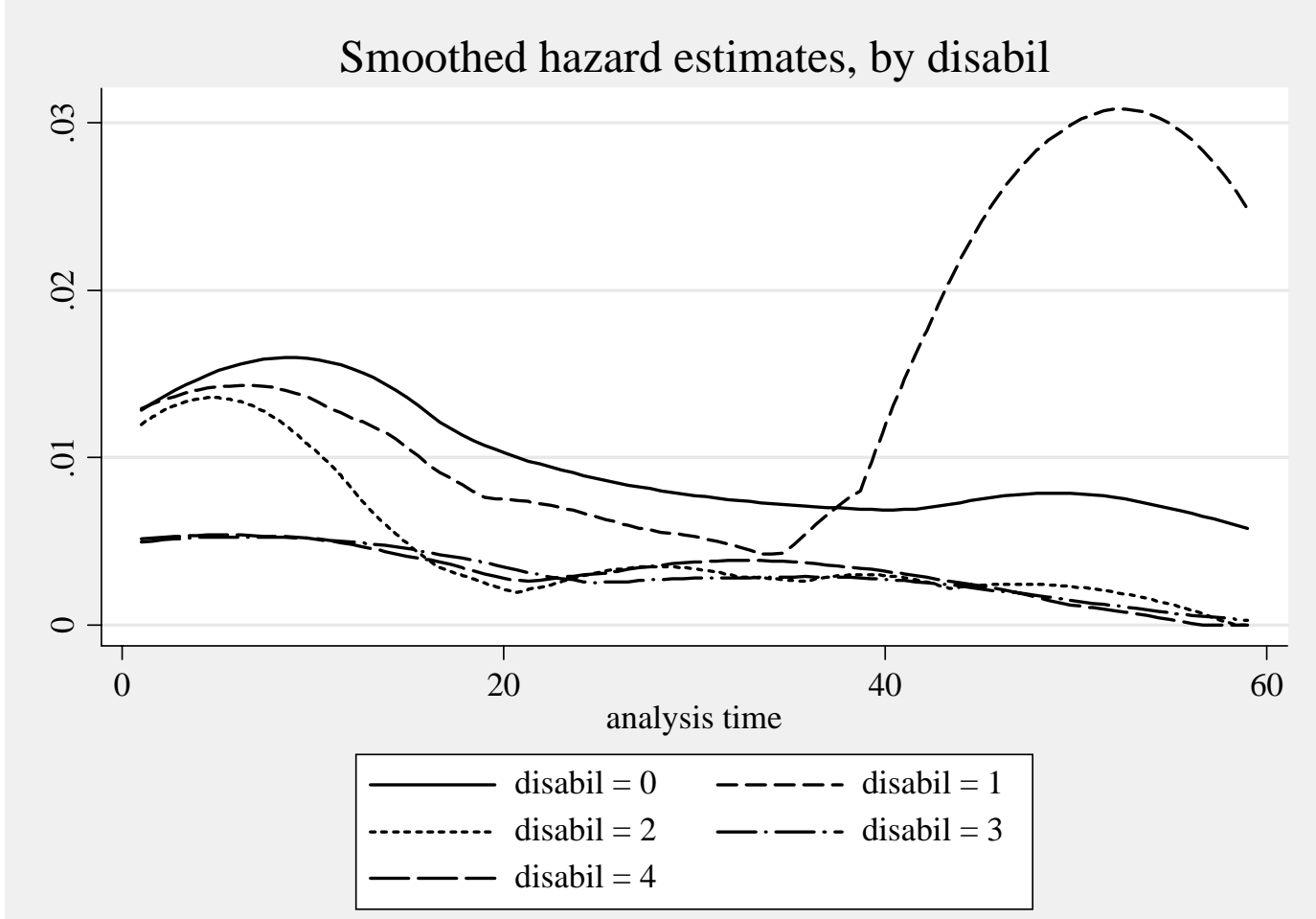

Source: our elaboration on IEFP data

$0=$ No disability

$1=$ Mental disability

2 = Organic disability

$3=$ Muscular/Skeletal disabilities

$4=$ Other disabilities

Figure 2. Baseline Hazard Contribution Cox PH Model

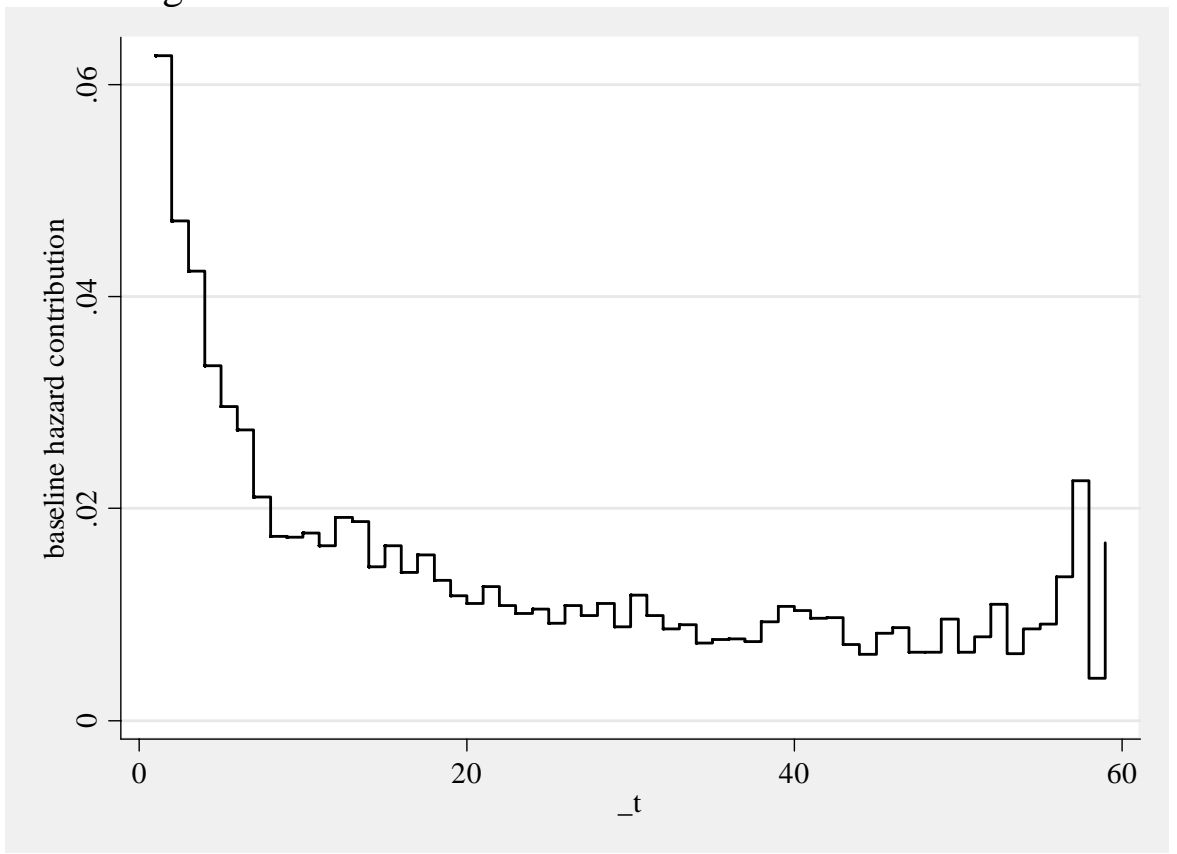

